\title{
Metastasis in the mandibular condyle: a case report
}

\author{
Mina Dodo ${ }^{{ }^{*}}$, Masahiro Kumagai ${ }^{2}$, Yuta Kato ${ }^{3}$, Hisashi Hirakawa ${ }^{4}$ and Takeyoshi Koseki ${ }^{1}$
}

\begin{abstract}
Background: Most bone metastases are observed in the trunk of the body. Metastasis in the mandibular condyle is rare. In many case reports, temporary common temporomandibular joint disorder-like symptoms can be a sign of relapse and metastasis.

Case presentation: We report a rare case of breast carcinoma metastatic to the left mandibular condyle in a 55year-old Japanese woman, who visited our department for a dental check-up prior to chemotherapy. She had almost no symptoms, but radiographs suggested the existence of metastasis.

Conclusions: In many case reports, patients had some symptoms. In this case report, our patient had slight symptoms, but we were able to confirm the metastasis from the symptoms and panoramic dental radiograph. When patients complain about discomfort of the temporomandibular joint, we need to consider the possibility of metastasis and notice changes on the panoramic dental radiograph.
\end{abstract}

Keywords: Temporomandibular joint, Metastasis, Radiographic finding

\section{Background}

Bone metastasis is reportedly found in 65 to $75 \%$ of patients with advanced-stage breast cancer. Most bone metastases are observed in the trunk of the body. In contrast, metastasis in the mandibular condyle is rare. The purpose of this study is to present a case of a patient with metastasis in the left mandibular condyle originating from breast cancer that showed slight and temporary common temporomandibular joint disorder (TMD)-like symptoms.

Case reports of metastatic lesions in the mandibular condyle that were written in English and published between 2000 and 2016 were identified through searches of databases. The clinical and radiographic characteristics of the metastatic lesions in the mandibular condyle were discussed.

\section{Case presentation}

A 55-year-old Japanese woman visited our department for a dental check-up prior to chemotherapy for breast

\footnotetext{
* Correspondence: minadodo@dent.tohoku.ac.jp

${ }^{1}$ Division of Preventive Dentistry, Department of Oral Health and Development Sciences, Tohoku University Graduate School of Dentistry, Sendai, Japan

Full list of author information is available at the end of the article
}

cancer. She had a medical history of ovarian tumor, and her ovary and uterus had been removed. One month before (August 2009), at the same time that she felt stiffness in her left breast, she felt sudden trismus and difficulty with chewing. However, she had no pain and gradually recovered from these symptoms without any treatment.

At the initial consultation (September 30, 2009), she had no trismus, pain, or swelling, but showed a slight deviation to the left side when she opened her mouth. The maximum incisal opening distance was $40 \mathrm{~mm}$. A tumor-forming ulcer $(10 \mathrm{~cm} \times 9 \mathrm{~cm})$ was observed in her breast. Positron emission tomography (PET) showed the tumor with a maximum standardized uptake value $\left(\mathrm{SUV}_{\max }\right)$ of 18 filling most of her right breast. Metastatic lymph nodes, bone lesions, and a lung lesion were also observed.

A panoramic dental radiograph and computed tomography $(C T)$ radiograph showed the destruction of the left mandibular condyle (Figs. 1 and 2). On magnetic resonance imaging (MRI), a relatively well-defined unstructured mass was observed on both T1-weighted (T1W) and T2-weighted (T2W) imaging (Fig. 3). PET showed multiple lesions, including in the vertebrae, costal bones, 


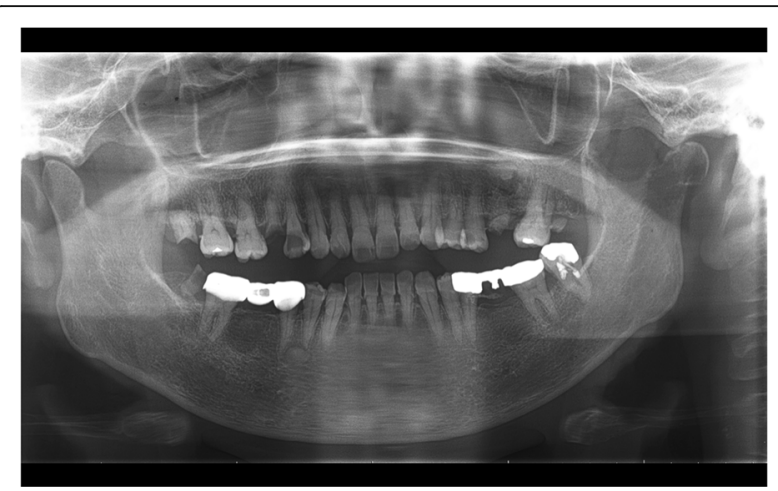

Fig. 1 Panoramic dental radiograph. A radiolucent destructive lesion and pathologic fracture were seen in the left condyle

and left mandibular condyle (Fig. 4). Given the diagnosis of left breast cancer associated with multiple metastatic lesions, chemotherapy using fluorouracil, epirubicin and cyclophosphamide (FEC treatment) was employed. In 4 months, when six cycles of chemotherapy had been completed, a radiograph showed a reduction in the size
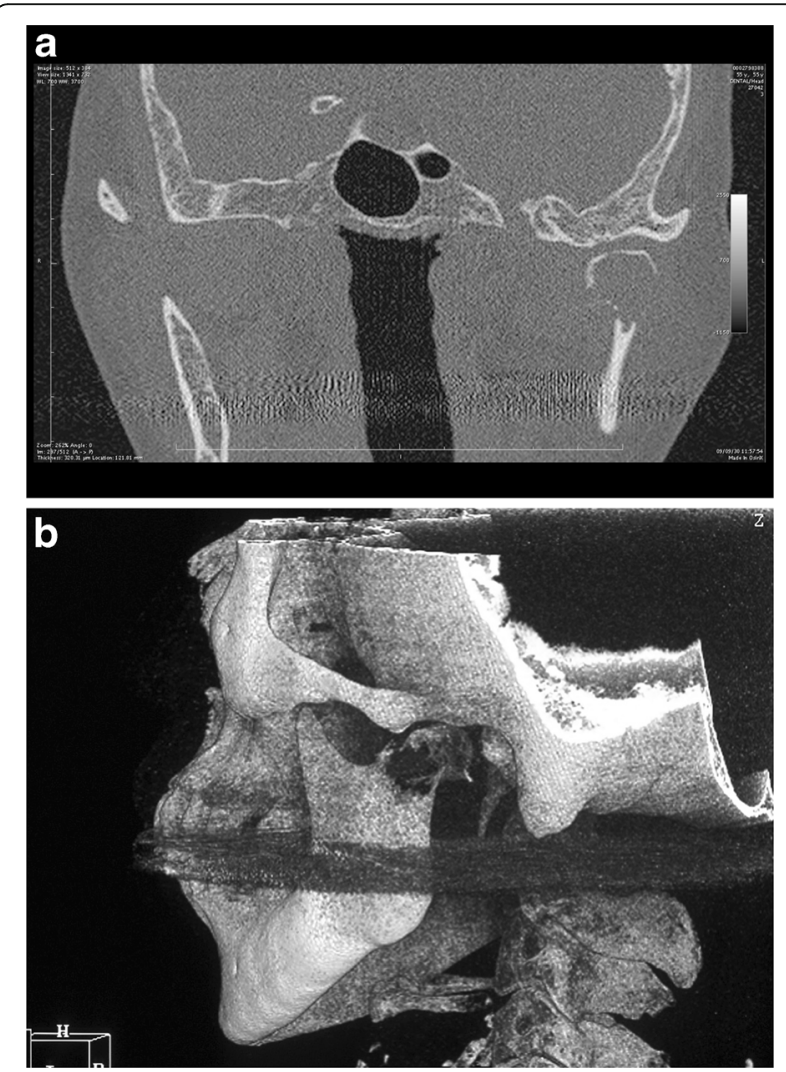

Fig. 2 Computed tomography radiographs. a Computed tomography radiograph (coronal plane). A radiolucent destructive lesion of the left condyle was observed. The cortical bone at the condyle was thin and partially fractured. $\mathbf{b}$ Computed tomography radiograph (three-dimensional reconstruction). Destruction of the left mandibular condyle was observed

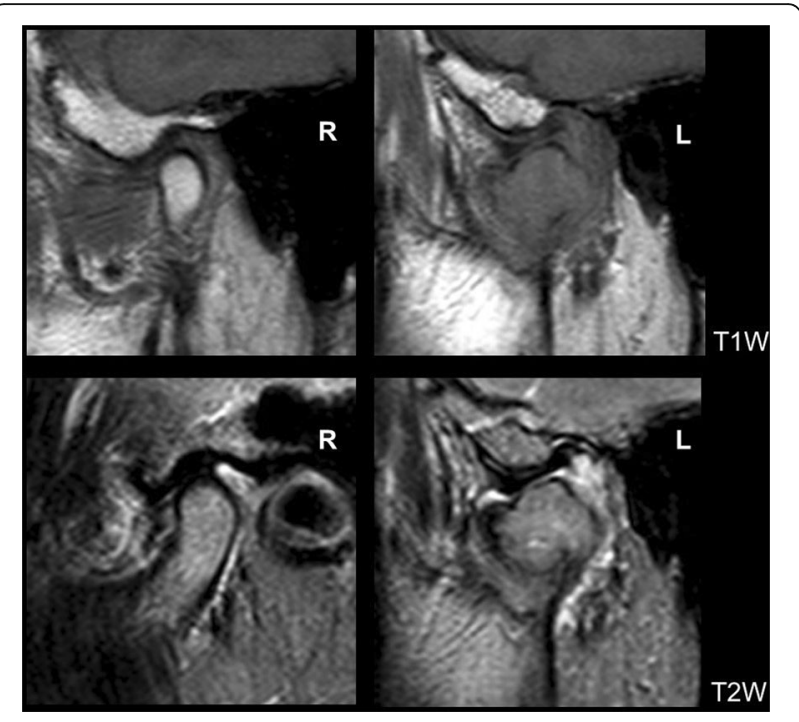

Fig. 3 Magnetic resonance image. The upper images were T1weighted and the lower images were T2-weighted. On the right side, the shape of the condyle was normal. An unstructured mass was observed in the left condylar region. A normal-shaped articular disc was seen on the destructed condyle

of both the primary and the metastatic lesions, including the left mandibular condylar lesion. An additional two cycles of chemotherapy were performed. Her general condition deteriorated. One and a half years after the first medical examination, she died.

\section{Discussion}

As PET showed multiple bone masses in addition to the extended primary left breast lesion, our patient was diagnosed with breast cancer associated with multiple metastases. A biopsy of a sample from the left condyle was not performed, and pathologic diagnosis of the left condylar lesion was not available. Nevertheless, after the FEC treatment, the lesions, including the one in the left condyle, appeared to be reduced on the radiograph investigation, which suggested that the left condylar lesion as well as the multiple bone lesions had the same characteristics as the breast adenocarcinoma. From this clinical finding, the left condylar lesion was speculated to have been a metastatic lesion from the breast cancer.

Between 2000 and 2016, 19 case reports (24 cases) of metastasis to the condyle were published. The primary tumor was diagnosed as breast cancer in five cases, lung cancer in five cases, and prostate, colon, and kidney cancer in two cases, respectively. According to the reports (Table 1), at the first consultation, most of the cases involved obvious subjective symptoms such as pain (16 out of 22), swelling (15 out of 22), and trismus (8 out of 


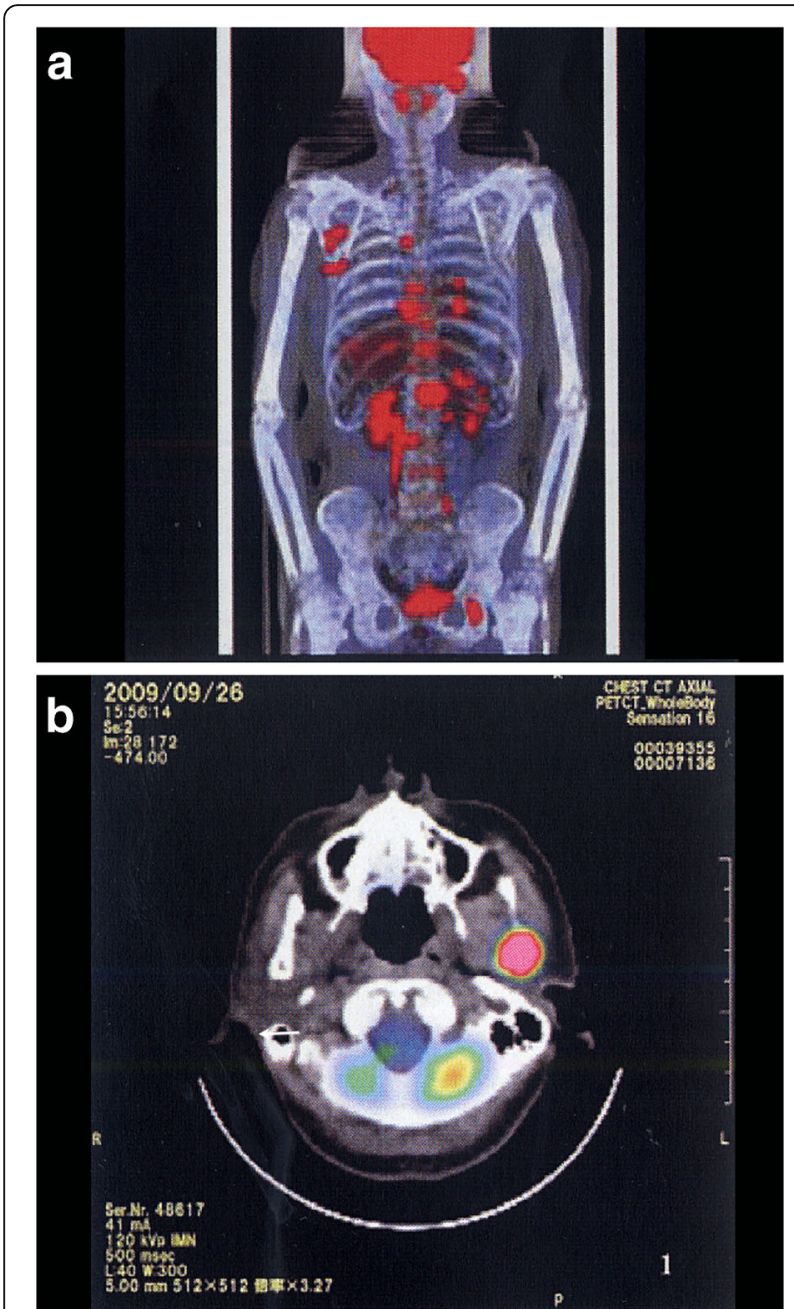

Fig. 4 Positron emission tomography. Positron emission tomography showed multiple high-uptake lesions, including one in the left temporomandibular joint condyle

22). In most of the cases (six out of seven), a panoramic dental radiograph was performed, and bone destruction and absorption were recognized. In this case, our patient visited our department for a dental check-up before receiving chemotherapy for breast cancer. She did not have any severe symptoms at the first consultation. However, the condylar lesion was recognized at the same time as multiple other metastases on PET. A panoramic dental radiograph showed destruction. Several previous reports (10 out of 22 ) claimed that the mandibular condyle could be the first recognized metastatic region. Additionally, other reports (12 out of 22) stated that TMD-like symptoms can be a sign of relapse and metastasis. Because of the development of cancer treatment, the number of patients with a history of cancer treatment is increasing. When patients complain about discomfort of the temporomandibular joint, we need to
Table 1 Case reports of metastatic tumors of the temporomandibular joint (from 2000 to 2013)

\begin{tabular}{|c|c|c|c|c|c|c|c|c|c|}
\hline $\begin{array}{l}\text { Primary } \\
\text { lesion }\end{array}$ & Sex & $\begin{array}{l}\text { Age } \\
\text { (years) }\end{array}$ & Pain & Swelling & Trismus & $\begin{array}{l}\text { Other } \\
\text { complaints }\end{array}$ & ${ }^{* 1}$ & ${ }^{*} 2$ & $\overline{\text { Author }}$ \\
\hline Bladder & M & 49 & $\circ$ & $\circ$ & & & 访 & & [1] \\
\hline Prostate & M & 85 & & $\circ$ & & Discomfort & $i$ & & \\
\hline Lung & $\mathrm{F}$ & 62 & $\circ$ & & & $\begin{array}{l}\text { Lower lip } \\
\text { numbness }\end{array}$ & $\hat{i}$ & & \\
\hline Penis & M & 53 & & $\circ$ & & Numbness & & 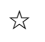 & \\
\hline Colon & M & 64 & $\circ$ & $\circ$ & & & & is & \\
\hline Breast & $\mathrm{F}$ & 47 & $\circ$ & & & & & it & \\
\hline Renal cell & $\mathrm{F}$ & 59 & & $\circ$ & $\circ$ & & & is & {$[2]$} \\
\hline Breast & M & 73 & $\circ$ & $\circ$ & & & 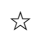 & & [3] \\
\hline Prostate & M & 75 & $\circ$ & $\circ$ & $\circ$ & & & $\hat{i}$ & {$[4]$} \\
\hline Lung & M & 49 & $\circ$ & $\circ$ & & & $\hbar$ & & {$[5]$} \\
\hline Breast & $\mathrm{F}$ & 51 & $\circ$ & $\circ$ & $\circ$ & & & $\dot{s}$ & {$[6]$} \\
\hline Lung & M & 51 & $\circ$ & $\circ$ & ० & & is & & {$[7]$} \\
\hline Breast & $\mathrm{F}$ & 42 & $\circ$ & $\circ$ & & & & 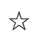 & {$[8]$} \\
\hline Lung & M & 60 & & & ० & $\begin{array}{l}\text { Limitation } \\
\text { of } \\
\text { mandibular } \\
\text { movement }\end{array}$ & is & & {$[9]$} \\
\hline Breast & $\mathrm{F}$ & 78 & $\circ$ & & $\circ$ & & & $i$ & {$[10]$} \\
\hline Stomach & M & 67 & & & & $\begin{array}{l}\text { Progressive } \\
\text { facial } \\
\text { asymmetry }\end{array}$ & & $\dot{s}$ & {$[11]$} \\
\hline Cystosarcoma & $\mathrm{F}$ & 58 & $\circ$ & & & $\begin{array}{l}\text { Hearing } \\
\text { difficulty }\end{array}$ & & $\dot{s}$ & [12] \\
\hline Lung & $\mathrm{F}$ & 71 & $\circ$ & & & $\begin{array}{l}\text { Changes in } \\
\text { occlusion } \\
\text { and } \\
\text { functional } \\
\text { limitation }\end{array}$ & is & & {$[13]$} \\
\hline Chordoma & $\mathrm{F}$ & 63 & $\circ$ & $\circ$ & $\circ$ & & & $i$ & {$[14]$} \\
\hline Renal cell & M & 49 & & & & $\begin{array}{l}\text { An } \\
\text { enlarging } \\
\text { painless left } \\
\text { mandibular } \\
\text { mass }\end{array}$ & 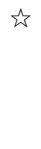 & & [15] \\
\hline Colon & M & 73 & $\circ$ & $\circ$ & & & is & & {$[16]$} \\
\hline Liver & M & 59 & $\circ$ & $\circ$ & $\circ$ & & & 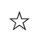 & {$[17]$} \\
\hline Uterine cervix & $\mathrm{F}$ & 65 & $\circ$ & $\circ$ & $\circ$ & & & 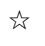 & {$[18]$} \\
\hline Uterine cervix & $\mathrm{F}$ & 63 & $\circ$ & $\circ$ & & & & is & [19] \\
\hline
\end{tabular}

${ }^{*} 1: \sum$ =the cases whose temporomandibular joint lesion was found before the primary lesion was recognized

$2: i z=$ the cases whose temporomandibular joint symptoms was a sign of a relapse and metastasis of the disease

$M$ male, $F$ female, o subjective symptoms

consider the possibility of metastasis and notice changes on the panoramic dental radiograph.

\section{Conclusions}

We report a case of a patient with metastatic lesion in the mandibular condyle from breast cancer. Our patient had slight and common TMD-like symptoms. Dentists and oral surgeons should keep in mind the possibility of metastatic lesion in the mandibular 
condyle and should be familiar with its clinical and radiographic characteristics.

\section{Acknowledgements}

Not applicable.

\section{Funding}

No source of funding.

\section{Availability of data and materials}

The datasets used during the current study available from the corresponding author on reasonable request.

\section{Authors' contributions}

MK, YK, and HH collected data and followed up the patient. MD and MK participated in the design of the study and drafted the manuscript. TK drafted and corrected the manuscript. All authors read and approved the final manuscript.

\section{Ethics approval and consent to participate}

Our research was based on guidance about patient privacy protection and ethics in medical science research defined by the Japanese Society of Oral and Maxillofacial Surgeons.

\section{Consent for publication}

Written informed consent was obtained from the patient for publication of this case report and any accompanying images. A copy of the written consent is available for review by the Editor-in-Chief of this journal.

\section{Competing interests}

The authors declare that they have no competing interests.

\section{Publisher's Note}

Springer Nature remains neutral with regard to jurisdictional claims in published maps and institutional affiliations.

\section{Author details}

'Division of Preventive Dentistry, Department of Oral Health and Development Sciences, Tohoku University Graduate School of Dentistry, Sendai, Japan. ${ }^{2}$ Department of Oral and Maxillofacial Surgery, Tohoku Kosai Hospital, Sendai, Japan. ${ }^{3}$ Department of Dentistry and Oral and Maxillofacial Surgery, Hamamatsu University School of Medicine, Hamamatsu, Japan.

${ }^{4}$ Department of Surgery, Tohoku Kosai Hospital, Sendai, Japan.

Received: 9 February 2017 Accepted: 12 September 2017

Published online: 16 November 2017

\section{References}

1. Qiu YT, Yang C, Chen MJ, Qiu WL. Metastatic spread to the mandibular condyle as initial clinical presentation: radiographic diagnosis and surgical experience. J Oral Maxillofac Surg. 2013;71:809-20.

2. Kelles M, Akarcay M, Kizilay A, Samdanci E. Metastatic renal cell carcinoma to the condyle of the mandible. J Craniofac Surg. 2012;23:302-3.

3. Gonzalez-Perez LM, Infante-Cossio P, Crespo-Torres S, Sanchez-Gallego F. Mandibular metastases as first clinical sign of an occult male breast cancer. Int J Oral Maxillofac Surg. 2012;41:1211-4.

4. Freudlsperger C, Kurth R, Werner MK, Hoffmann J, Reinert S. Condylar metastasis from prostatic carcinoma mimicking temporomandibular disorder: a case report. Oral Maxillofac Surg. 2012;16:79-82.

5. Tabib R, Elias S, Tal Y, Ben-Yehuda A, Abu-Tair J. Temporomandibular jointrelated symptoms as initial presentation of lung carcinoma in a patient with Takayasu's arteritis. J Oral Maxillofac Surg. 2010;69:226-9.

6. Patricia A, Kaba SP, Trierveiler MM, Shinohara EH. Osteoblastic metastasis from breast affecting the condyle misinterpreted as temporomandibular joint disorder. Indian J Cancer. 2011;48:252-3.

7. Katsnelson A, Tartakovsky JV, Miloro M. Review of the literature for mandibular metastasis illustrated by a case of lung metastasis to the temporomandibular joint in an HIV-positive patient. J Oral Maxillofac Surg. 2010;68:1960-4.
8. Menezes AV, Lima MP, Mendonca JE, Haiter-Neto F, Kurita LM. Breast adenocarcinoma mimicking temporomandibular disorders: a case report. J Contemp Dent Pract. 2008;9:100-6.

9. Boniello R, Gasparini G, D'Amato G, Di Petrillo A, Pelo S. TMJ metastasis: a unusual case report. Head Face Med. 2008;4:8.

10. Miles BA, Schwartz-Dabney C, Sinn DP, Kessler HP. Bilateral metastatic breast adenocarcinoma within the temporomandibular joint: a case report. J Oral Maxillofac Surg. 2006;64:712-8.

11. Smolka W, Brekenfeld C, Buchel P, lizuka T. Metastatic adenocarcinoma of the temporomandibular joint from the cardia of the stomach: a case report. Int J Oral Maxillofac Surg. 2004;33:713-5.

12. Deeming G, Divakaran R, Butterworth D, Foster M. Temporomandibular region metastasis from cystosarcoma phyllodes: a case report and review of the literature. J Craniomaxillofac Surg. 2003;31:325-8.

13. Shintaku WH, Venturin JS, Yepes JF. Application of advanced imaging modalities for the diagnosis of metastatic adenocarcinoma of the lungs in the temporomandibular joint. Oral Surg Oral Med Oral Pathol Oral Radiol Endod. 2009;107:e37-41.

14. Meneghini F, Castellani A, Camelin N, Zanetti U. Metastatic chordoma to the mandibular condyle: an anterior surgical approach. J Oral Maxillofac Surg. 2002;60:1489-93.

15. Yoskovitch A, Nquyen $L H$, Sadeghi N, Auqer M. Renal cell carcinoma presenting as a mandibular mass. Otolanyngol Head Neck Surg. 2001;125:654-5.

16. Mason AC, Azari KK, Farkas LM, Duvvuri U, Myers EN. Metastatic adenocarcinoma of the colon presenting as a mass in the mandible. Head Neck. 2005;27:729-32.

17. Kamatani T, Tatemoto $Y$, Tateishi $Y$, Yamamoto $T$. Isolated metastasis from hepatocellular carcinoma to the mandibular condyle with no evidence of any other metastases: a case report. Br J Oral Maxillofac Surg. 2008;46:499-501.

18. Sugiyama G, Ohyama Y, Kiyoshima T, Shimizu M, Kaneki E, Takenoshita Y. Metastatic adenocarcinoma of the mandibular condyle from uterine cervix: report of a case. Oral Sci Int. 2014;11:40-4.

19. Puranik AD, Purandare NC, Dua S, Deodhar K, Shah S, Agrawal A, Rangarajan $V$. Isolated mandibular condylar metastases: an uncommon manifestation of recurrent cervical cancer. J Cancer Res Ther. 2013;9:108-10.

\section{Submit your next manuscript to BioMed Central} and we will help you at every step:

- We accept pre-submission inquiries

- Our selector tool helps you to find the most relevant journal

- We provide round the clock customer support

- Convenient online submission

- Thorough peer review

- Inclusion in PubMed and all major indexing services

- Maximum visibility for your research

Submit your manuscript at www.biomedcentral.com/submit
) Biomed Central 